\title{
Hydrological monitoring and seasonal forecasting: Progress and perspectives
}

\author{
TANG Qiuhong ${ }^{1}$, ZHANG Xuejun ${ }^{1,6}$, DUAN Qingyun ${ }^{2}$, HUANG Shifeng ${ }^{3}$, \\ YUAN Xing ${ }^{4}$, CUI Huijuan ${ }^{5}$, LI Zhe ${ }^{1}$, LIU Xingcai ${ }^{1}$
}

1. Key Laboratory of Water Cycle and Related Land Surface Processes, Institute of Geographic Sciences and Natural Resources Research, CAS, Beijing 100101, China;

2. State Key Laboratory of Earth Surface Processes and Resource Ecology, College of Global Change and Earth System Science, Beijing Normal University, Beijing 100875, China;

3. Remote Sensing Technology Application Center, China Institute of Water Resources and Hydropower Research, Beijing 100038, China;

4. RCE-TEA, Institute of Atmospheric Physics, CAS, Beijing 100029, China;

5. Key Laboratory of Land Surface Pattern and Simulation, Institute of Geographic Sciences and Natural Resources Research, CAS, Beijing 100101, China;

6. University of Chinese Academy of Sciences, Beijing 100049, China

\begin{abstract}
Hydrological monitoring and seasonal forecasting is an active research field because of its potential applications in hydrological risk assessment, preparedness and mitigation. In recent decades, developments in ground and satellite measurements have made the hydrometeorological information readily available, and advances in information technology have facilitated the data analysis in a real-time manner. New progress in climate research and modeling has enabled the prediction of seasonal climate with reasonable accuracy and increased resolution. These emerging techniques and advances have enabled more timely acquisition of accurate hydrological fluxes and status, and earlier warning of extreme hydrological events such as droughts and floods. This paper gives current state-of-the-art understanding of the uncertainties in hydrological monitoring and forecasting, reviews the efforts and progress in operational hydrological monitoring system assisted by observations from various sources and experimental seasonal hydrological forecasting, and briefly introduces the current monitoring and forecasting practices in China. The grand challenges and perspectives for the near future are also discussed, including acquiring and extracting reliable information for monitoring and forecasting, predicting realistic hydrological fluxes and states in the river basin being significantly altered by human activity, and filling the gap between numerical models and the end user. We highlight the importance of understanding the needs of the operational water management and the priority to transfer research knowledge to decision-makers.
\end{abstract}

Keywords: hydrological monitoring; hydrological forecasting; uncertainty; modeling; remote sensing; climate model

Received: 2016-01-06 Accepted: 2016-03-21

Foundation: National Natural Science Foundation of China, No.41425002; National Basic Research Program of China, No.2012CB955403; National Youth Top-notch Talent Support Program in China; China Special Fund for Meteorological Research in the Public Interest (Major projects), No.GYHY201506001-7; The Beijing Science and Technology Plan Project, No.Z141100003614052

Author: Tang Qiuhong, PhD and Professor, E-mail: tangqh@igsnrr.ac.cn 


\section{Introduction}

Hydrological extremes such as drought and flood events have frequently struck many parts of the world in the past few decades (Andreadis et al., 2005; Zhai et al., 2010; Wang et al., 2011a) and are likely to become more frequent under a changing climate (Milly et al., 2002; Leng et al., 2015, 2016; Hirabayashi et al., 2008, 2013). These hydrological extremes usually bring significant and far-reaching impacts to the economy, society and environment. The reported annual losses from droughts and floods reached tens of billions of U.S. dollars, with thousands of people killed (Hirabayashi et al., 2013) and millions of people affected each year across the world (Wilhite, 2000; Below et al., 2007). One possible reason for such huge losses is the lack of prompt risk response strategies due to the scarcity of accurate drought/flood early-warning information. A hydrological monitoring and seasonal forecasting system is able to provide a reasonable quantitative measurement of land surface hydrological conditions in a real-time manner and predict their variations up to several months ahead, which will greatly benefit risk assessment, preparedness and mitigation.

Presently, numerous studies have been devoted to hydrological monitoring and seasonal forecasting, with the monitoring techniques varying from the in-situ/satellite measurements to model simulations and the forecasting approaches varying from statistical methods to physical hydrological models. This study synthesizes the past achievements of hydrological monitoring and seasonal forecasting, highlights the current challenges, and paints the future picture. The rest of the paper is organized as follows. Section 2 focuses on the uncertainties of the hydrological monitoring and forecasting. Sections 3 and 4 give general overviews regarding to the hydrological monitoring and seasonal forecasting respectively, and Section 5 summaries the available practices in China. The present challenges and the future perspectives are highlighted in Section 6.

\section{Uncertainties in hydrological monitoring and forecasting}

Reliable and accurate hydrological monitoring and forecasting are two keys for better hydrological services and water resources management decision-making. However, both hydrological monitoring and forecasting are plagued by various sources of uncertainties, which often put their usefulness into questions. There are two kinds of uncertainties: (1) the epistemic uncertainty which arises due to lack of knowledge of a quantity of interest, sometimes also known as subjective uncertainty; (2) aleatoric uncertainty, which is an inherent variation associated with a quantity, also called as natural variability or stochastic uncertainty. The former uncertainties are to be reduced, while the latter ones are to be quantified. In the following, we discuss the uncertainties associated with hydrological monitoring and forecasting separately, and suggest the ways to quantify or reduce them.

\subsection{Uncertainties in hydrological monitoring}

Two kinds of uncertainties occur in hydrological monitoring, one from the data generation stage and the other from data processing stage. The uncertainties from the data generation stage can be random noises during measurements or errors due to factors such as improper use of the equipment, and/or human errors in obtaining, processing and communicating the monitoring data. The uncertainties from the data processing stage may come from the in- 
herent limitations of the monitoring methods or due to human errors. For example, when gauge-based in-situ monitoring data is used to represent a quantity over a spatial domain, sampling errors are bound to occur (e.g., estimating precipitation over a spatial domain based on rain gauge data). This kind of errors may be reduced by introducing more gauges in the analysis. On the other hand, remote sensing data is promising to provide a spatial estimate of a quantity by inferring it from the optical signals, but the accuracy of such techniques is highly dependent on the inversion algorithms used to convert the optical signals into the quantities of interest. Many of those inversion algorithms are built based on empirical, statistical relationships between the signals and the quantities of interest that are far from being precise. Further, the satellite signal sources are often contaminated by the obstacles between the sensors and the objects (e.g., clouds, water surfaces, among others).

In general, the errors in monitoring data are manifested in three forms: (1) systematic errors, (2) random errors, and (3) spurious errors. The systematic errors are usually resulted from data generation stage as described above, and appropriate steps must be taken to correct them according to their error sources. Random errors can be corrected readily using methods such as Kriging, artificial neural network (ANN), or other statistical methods. For these errors, statistical assumptions are often made about their properties (i.e., probability distributions). Gaussian distribution is the most often used probability distribution for many variables (e.g., surface air temperature, surface air pressure, geometric measurements). However, for certain variables, other distributions must be used, for example, Gamma type distributions for precipitation errors or streamflow discharge errors. The spurious errors may be readily detectable, but are not easy to correct. Those errors are usually associated with subjective, human errors in the data generation or processing stage (e.g., coding errors, misreading of the numbers, or improper use of equipment).

\subsection{Uncertainties in hydrological forecasting}

Hydrological forecasting is generally made with a hydrological model, which may be based on statistical input-output relationships (i.e., black-box model or system models), or observed or assumed empirical relationships among various hydrological variables (i.e., conceptual models), or physical laws of mass, energy and momentum conservations (i.e., physically based models). All hydrological models involve hydrological inputs (e.g., precipitation, surface air temperature, potential evapotranspiration) and outputs (e.g., streamflow, actual evapotranspiration, snowmelt). In conceptual or physically based models, there are also hydrological state variables (e.g., soil moisture content, areal snow coverage, snow depth, and lake water level). Uncertainties exist in all phases of hydrological modeling, including hydrological inputs, hydrological state variables, model structure and parameters, model outputs, and all related observational data.

Errors in hydrological inputs are generally of two types: the errors associated with the observations and the errors associated with the forecasts. The observational errors are the errors carried over from hydrological monitoring, as discussed in Section 2.1. When monitoring data such as precipitation or surface air temperature datasets are used as inputs to a hydrological model, one must first ensure that the uncertainties in those datasets are reduced or quantified. The forecasting errors usually refer to the errors in precipitation or temperature forecasts generated by a numerical weather or climate model (e.g., QPF - quantitative 
precipitation forecast or QTF - quantitative temperature forecasts). All raw QPFs and QTFs contain biases, and they are usually incompatible with a given hydrological model because of the scale difference between them. Further the uncertainties in the forecasts are generally greater than that associated with the observations. Statistical post-processing methods have been widely used to deal with the errors in QPFs and QTFs (Glahn and Lowry, 1972; Krzysztofowicz and Sigrest, 1999; Schaake et al., 2007). Data assimilation methods have been widely used to reduce the uncertainty associated with the initial conditions (ICs) used in the hydrological models. Popular data assimilation methods include ensemble Kalman Filter (EnKF) method, the 3-dimensional and 4-dimensional variational methods (3dVAR and 4dVAR) (Evensen, 1997; Wang et al., 2008; Huang et al., 2009). The effects of using data assimilation methods to merge observational data and model state variables have shown to be significant in improving hydrological forecasting (Clark et al., 2008; Liu et al., 2012).

Model calibration is a process in which model parameters are tuned to best match model predictions with corresponding observations (Duan et al., 2006). Many advances have been made in terms of using model calibration methods to reduce the uncertainties inherent in the specification of model parameters (Duan et al., 1992; Beven and Binley, 1992; Wang et al., 2014, 2016). As hydrological models are highly nonlinear, treating uncertainties in different phases of hydrological modeling independently may lead to biased model parameter estimates. Recently, integrated approaches to model calibration have been becoming an emerging area. For instance, Kavetski et al. (2002) proposed a Bayesian Total Error Analysis (BATEA) to address errors in model inputs and model parameters. Ajami et al. (2007) developed the Integrated Bayesian Uncertainty Estimation (IBUNE) method to consider errors in model inputs, model parameters and model structure.

Model structural errors are a fact of life as all models are just simplifications of the real world systems. To deal with the model differences, many multi-model ensemble approaches have emerged, including Bayesian Model Averaging (BMA) methods proposed by Raftery et al. (2005) and superensemble approach (Krishnamurti et al., 1999), which strive to obtain consensus model predictions by weighing model predictions based on their consistency with observations. Ensemble forecasting approach has not only been used to develop multi-model predictions, it is also a popular approach in treating uncertainties from different sources, including model inputs, ICs, and model parameters. To date, human activities are posing significant influence to terrestrial water cycle (Gerten et al., 2008) directly by water withdrawals, like crop irrigation (Tang et al., 2008; Leng et al., 2013), reservoir regulation (Döll et al., 2009) and groundwater pumping (Leng et al., 2014; Ferguson and Maxwell, 2012) and indirectly by altering the land cover (VanShaar et al., 2002). How to effectively parameterize such human interventions into land surface hydrological models is of critical importance for an improved knowledge of terrestrial hydrological variations under a changing environment.

To better understand the uncertainty of seasonal hydrologic prediction, a few attempts have also been made to investigate the source of hydrological predictability, like exploring the potential linkage of ICs with the runoff variations using the statistical methods (e.g., Maurer et al., 2004), or employing an ensemble streamflow prediction (ESP) or reverse-ESP theoretical framework (Wood and Lettenmaier, 2008) to isolate the role of ICs and climate forecasts (CFs) (i.e., the hydrological inputs) in seasonal hydrological prediction at regional 
(e.g., Wood and Lettenmaier, 2008; Li et al., 2009; Yang et al., 2014; Shukla and Lettenmaier, 2011a; Staudinger and Seibert, 2014) and global scale (e.g., Shukla et al., 2013). Depending on which one of those factors dominates the seasonal hydrological predictability, targeted efforts can be put forward to reduce the uncertainties associated with that dominant factor (ICs or CFs), and thus enhances the seasonal hydrological forecast skills.

\section{Hydrological monitoring, observations and data assimilation}

Hydrological monitoring is able to provide real-time quantitative information of hydrological fluxes and states. An accurate monitoring is not only of great value for real-time assessment of the hydrological extremes (e.g., drought/flood), but also is the key premise for hydrological prediction.

In-situ measurement is a routine way to provide the ground truth of land surface hydrological fields. In present, the real-time hydrological information networks have been established and made available in some countries, such as the National Water Information System (NWIS) in the U.S. (http://waterdata.usgs.gov/nwis), the Hydrological Information Inquiry System (HIIS) in China (http://www.hydroinfo.gov.cn/). Although with great potential to serve as the ground reference for model verifications, such direct measuring technique usually suffers from the inconsistency at spatial and temporal scales, which hampers its effective use at a large scale (Tang et al., 2009b; Pan et al., 2012; Li et al., 2013). More importantly, several key variables, like the terrestrial water storage (TWS), are still hard to directly measure at the monitoring sites.

Satellite remote sensing, featured with high temporal frequency and spatial continuity, provides an alternative opportunity for large-scale observations of land surface hydrological variables. Through combining multi-sensor microwave and infrared data with different algorithms, a few satellite-based global precipitation products, like TRMM Multi-satellite Precipitation Analysis (TMPA) (Huffman et al., 2007) and the latest Global Precipitation Measurement (GPM) mission (Hou et al., 2014), have been generated and investigated with great potentials for flood/drought monitoring (Hong et al., 2007; Zeng et al., 2012; Zhao et al., 2015). The satellite-based evapotranspiration (ET) can be successfully estimated in real-time as given the real-time inputs from Moderate Resolution Imaging Spectroradiometer (MODIS) and surface radiation products derived from geostationary satellites (Tang et al., 2009c). The near-surface (i.e. the top few millimeters to centimeters) soil moisture content can be operationally estimated with passive microwave remote sensing products like the Advanced Microwave Scanning Radiometer 2 (AMSR2) (Fujii et al., 2009; Kim et al., 2015), or the combination of active and passive frequencies like the Soil Moisture Active Passive (SMAP) mission (Entekhabi et al., 2010). Some passive and active merged products, such as the European Space Agency Climate Change Initiative (ESA CCI) soil moisture retrievals, are being used to monitor short-term droughts (Yuan et al., 2015a). With the aid of the passive microwave data from the Special Sensor Microwave Imager/Sounder (SSMIS), the National Snow and Ice Data Center (NSIDC) can update global sea ice concentrations and snow extent in near real-time (https://nsidc.org/data/nise1). The advent of Gravity Recovery and Climate Experiment (GRACE) made it feasible to monitor the variations of TWS at a spatial scale of several hundred kilometers (Tapley et al., 2004). In addition, a few satellite-aided 
ellite-aided drought monitoring were carried out through detecting the changes in surface temperature or land cover (e.g., Li et al., 2010). Although the satellite remote sensing is promising, the non-closure of terrestrial water budgets is still an open issue (Tang et al., 2009b; Sheffield et al., 2009; Gao et al., 2010).

After decades of development, land surface hydrological modeling has gained great progress, which enables the large-scale consistent estimates of different components of terrestrial water cycle. So far, land surface hydrological models have been successfully implemented at both regional (e.g., Maurer et al., 2002; Yang et al., 2004; Tang et al., 2007, 2008; Hu et al., 2012; Zhang et al., 2014) and global scales (e.g., Sheffield and Wood, 2007, 2008; Haddeland et al., 2011; Pan et al., 2012). With the aid of real-time meteorological forcings, many model-based hydrological monitoring practices have been conducted to support a real-time flood/drought diagnosis. For example, an operational Global Flood Monitoring System (GFMS), based on the global real-time rainfall estimates from Tropical Rainfall Measuring Mission (TRMM) satellite and a distributed hydrological model, has been explored to provide the past 24-hour global streamflow information (Hong et al., 2007; Yilmaz et al., 2010; Wu et al., 2014). Unlike the flood risk, drought is inherently defined in the context of a long-term climatology (Andreadis and Lettenmaier, 2006; Shukla et al., 2011b), and thus requires the real-time hydrological estimates (e.g., runoff, soil moisture) to be consistent with the long-term retrospective simulations. Actually, the gauge-based meteorological data used for retrospective simulations are barely reported in real-time manner due to the time latency for quality controlling. Thus, a main challenge for an operational drought monitoring is the inconsistency of real-time meteorological forcings and gauge-based observations (Tang et al., 2009a; Tobin and Bennett, 2010; Sheffield et al., 2014; Nijssen et al., 2014; Zhang and Tang, 2015). To resolve this issue, Tang et al. (2009a) proposed an index station percentile method (ISPM) to estimate the real-time precipitation of all index stations based on the limited number of real-time stations. Alternatively, when the satellite data is used as real-time source of model drivers, an equal quantile mapping method was usually employed to remove its systematic bias relative to ground observations (Tobin and Bennett, 2010; Zhang and Tang, 2015). By doing so, the real-time hydrological estimates can be directly compared with the multi-decadal retrospective simulations and thus greatly benefits the real-time drought diagnosis and detection (Sheffield et al., 2014). Following this way, a few experimental drought monitoring systems have been correspondingly established at continental (Wood and Lettenmaier, 2006) and global scale (Nijssen et al., 2014).

It has been demonstrated that a single data source (e.g., in-situ/satellite measurement, land surface modeling) is insufficient to comprehensively understand the land surface hydrologic states and fluxes as well as their spatial and temporal variations across different scales (Pan et al., 2008). It is essential to produce a set of optimal hydrological estimates, which can comprehensively harness the advantage from different data sources (Pan et al., 2012). To this end, the data assimilation scheme, which can blend the sparse land observations with the background fields from land surface hydrological modeling, was introduced to improve the model-derived hydrological estimates. Presently, several studies have made considerable attempts to assimilate the satellite- and ground-based SWE observations (Andreadis and Lettenmaier, 2006; De Lannoy et al., 2010, 2012) and/or soil moisture (Han et al., 2014) into the modeling. Moreover, for a comprehensive identification of drought, a GRACE Data 
Assimilation System, based on the incorporation of the GRACE-based TWS into the Catchment Land Surface Model (CLSM) (Zaitchik et al., 2008), has been successfully applied into the North American Drought Monitor (NADM) system to fill up the ignored subsurface water storage information (Houborg et al., 2012). Coincidently, there are also a large number of operational data assimilation systems that have been made publicly available at large scale to provide the multi-source-based optimal fields, such as the Global Land Data Assimilation System (GLDAS) (Rodell et al., 2004), North American Land Data Assimilation System (NLDAS) (now upgraded to Phase 2 (NLDAS-2)) (Mitchell et al., 2004), European Land Data Assimilation System (ELDAS), and West China Land Data Assimilation System (WCLDAS) (Li et al., 2004). Therefore, the data assimilation approach is being a promising area to yield the 'best' hydrological monitoring.

\section{Seasonal hydrological forecasting}

Real-time monitoring is the base to predict the near future. With the advances in the monitoring techniques, and the improved understanding of global water cycle, predicting land surface hydrological conditions at seasonal time scales are being augmented from using statistical approaches to dynamical forecasting with physical hydrologic models and seasonal climate forecast models (see Figure 1 in Yuan et al., 2015c for a recent review).

The statistical-based hydrological forecast is mostly based on the long-term time series and limited to the single-variable outcome (e.g., streamflow). One common way is to regress seasonal streamflow volume on the corresponding hydro-climatic predictors (e.g., precipitation, temperature, and SWE) (Garen, 1992; Kwon et al., 2009; Pagano et al., 2009). Some other statistical methods, such as the independent component analysis (Westra et al., 2008), the nonparametric statistical analysis (Robertson and Wang, 2012; Di et al., 2014; Singh and Cui, 2015), were also largely employed for seasonal streamflow forecast. However, the statistical-based forecast model are usually trained with multi-decadal time series, leaving it hard to capture the transient relationship between the climatic predictors and predictand (e.g., streamflow), particularly in the context of a changing climate and non-stationary hydrology. Furthermore, volume of streamflow was simply recognized as the function of indicative predictors (e.g., precipitation, temperature, and streamflow) in this forecast approach, without describing the physical processes of the terrestrial water cycle.

Along with the advance in land surface hydrological models, the physical model-based seasonal forecast has been becoming popular. One example is the so-called ESP approach, wherein the climate forcings during the forecast period are taken from an ensemble of previous years for the same period (Day, 1985). Accordingly, the forecast skill of ESP is solely dependent on the knowledge of ICs such as initial snow and soil moisture. As a primary land surface moisture storage term, snowpack affects seasonal hydrological forecast skill over the snow-fed river basins (Maurer et al., 2004), particularly over those high-latitude (Yossef et al., 2013; Shukla et al., 2013) and mountainous regions (Staudinger and Seibert, 2014). For those regions with little snow impact, ESP forecast skill is mostly controlled by the antecedent soil moisture (Koster et al., 2010). Particularly, for the regions characterized with dry climate regime, the dominance of soil moisture condition can last for 3-month (Yuan et al., 2013a; Yang et al., 2014). This may be because the precipitation amount and variation are 
both low in the dry regions, leading to the weak influence of precipitation to the hydrological estimates (e.g., runoff and soil moisture) (Mo and Lettenmaier, 2014). In addition, the influence of ICs to seasonal hydrological predictability has an obvious interannual variability, e.g., with more important role in neutral years than in El Niño-Southern Oscillation (ENSO)-dominant years (Yuan et al., 2013b; Sinha and Sankarasubramanian, 2013). Through an assessment during the hydrological extremes, the role of ICs differs on the phase of hydrological extremes. Specifically, the knowledge of ICs during the drought development phase generally outweighs that during predicting the onset of drought (Thober et al., 2015).

The ESP approach was firstly implemented operationally by the National Weather Services (NWS) River Forecast Centers (Day, 1985), and was then augmented by relating the seasonal streamflow forecasts with large-scale remote climate indices (Hamlet and Lettenmaier, 1999; Werner et al., 2004, 2005; Wang et al., 2011b; van Dijk et al., 2013). Subsequently, a test bed for seasonal hydrological forecasting approach was proposed to predict soil moisture and runoff up to several months over the U.S., wherein the historical simulation (used to form a long-term climatology), the real-time monitoring (used to provide the real-time accurate forecast ICs), and the seasonal forecast (used to predict the hydrological outputs out to several months) were integrated within an operational system (Wood and Lettenmaier, 2006).

In addition to ICs, the strong ocean-atmosphere teleconnection, such as ENSO associated with the change in SST anomalies and winds in the tropical Pacific, is another primary source of seasonal hydrological predictability (Smith et al., 2012). The linkage of climate indices with seasonal hydrological predictability has been quantified over multiple river basins (Lan et al., 2003; Maurer et al., 2004; Bierkens et al., 2009; Liu et al., 2012; van Dijk et al., 2013). With the improved representation of such large-scale climate phenomena (e.g., ENSO) in coupled atmosphere-ocean general circulation models (CGCMs) (Barnston et al., 2012), predicting seasonal hydrology based on CGCMs has received considerable attentions over the recent years (Luo and Wood, 2008; Yuan et al., 2015a). Practically, one challenge for such CGCM-based forecast approach is that the spatial resolution of seasonal CFs is too coarse to be directly used as hydrological model inputs. This inspired many researchers to explore the downscaling methodologies, such as the unconditional Bias Correction and Spatial Downscaling (BCSD) method (Wood et al., 2002) and the conditional the Bayesian downscaling method (Luo et al., 2007). Aside from the statistical downscaling scheme, the dynamical downscaling method, which employs the advantage of regional climate models (RCMs) (i.e., with satisfactory representation of local climate response) to effectively reduce the CGCM forecast errors at daily-to-seasonal scales (Yuan and Liang, 2011), is being under explored as well. For example, the Multi-RCM Ensemble Downscaling (MRED) project was initiated by Climate Prediction Program for the Americas (CPPA) to conduct the multi-decadal ensemble downscaling experiments during the cold seasons, in which multiple RCMs were merged with National Centers for Environmental Prediction (NCEP) Climate Forecast System (CFS) (Yuan and Liang, 2011; De Sales and Xue, 2013; Shukla and Lettenmaier, 2013). The CGCM climate outputs, after appropriate downscaling procedures, can be directly used to force the hydrological model for seasonal prediction of hydrological fields. Previous studies have assessed the CGCM-based seasonal forecast skill for a 
multi-decadal hindcast period (e.g., Wood et al., 2005; Luo and Wood, 2008; Mo et al., 2012; Yuan et al., 2013b; Bastola et al., 2013; Mo and Lettenmaier, 2014), and broadly indicate that CGCM-based hydrological forecast skill has marginal improvement relative to ESP beyond 1 month. This suggests much more efforts are needed to improve the CGCMs' predictive skill, especially for those variables relevant to hydrology.

A CGCM-based drought monitoring and seasonal forecasting system, based on the seasonal climate forecasts from a newly developed CGCM (CFSv2; Saha et al., 2014), the Bayesian downscaling scheme and historic observations from the Phase 2 of the North American Land Data Assimilation system (NLDAS-2; Xia et al., 2012), were developed to carry out a Drought Forecast Analysis in support of the U.S. Seasonal Drought Outlook (Luo and Wood, 2007). In addition to the USA, similar experimental forecasting systems were developed over other continents like Europe (European Drought Observatory) (Vogt et al., 2011) and Africa (Yuan et al., 2013a; Sheffield et al., 2014), as well as to the global scale (Yuan et al., 2015b).

\section{Hydrological monitoring and forecasting practices in China}

Over the past few decades, China has experienced frequent hydrological extremes (e.g., drought and flood). In this context, numerous hydrological monitoring and seasonal forecast practices have been put in place for risk coping and reduction. Primarily, the Bureau of Hydrology $(\mathrm{BoH})$ established a comprehensive station-based monitoring network over China, which includes over 90,000 hydrometric stations (wherein there are over 3200 hydrological stations), to provide the real-time measurement of river flow regime. Subsequently, the corresponding operational systems, such as Hydrological Information Inquiry System (HIIS) and Information Service System (ISS), were extensively implemented to provide official information services for water resource managers and decision-makers (http://www.hydroinfo. gov.cn/). In addition to the BoH, the National Climate Center (NCC) at CMA initiated a drought monitoring platform to provide insight into the real-time meteorological drought diagnosis over China (http://cmdp.ncc.cma.gov.cn/en/). Recently, a China Drought Meteorology Scientific Research Project has been launched since 2015, aiming at improving the monitoring and understanding of droughts from meteorological perspective to those for agricultural and hydrological applications. The project is also targeted at developing a refined drought early warning system in northern China based on multiple global climate forecast models (Ma et al., 2015) and physical hydrologic models (Yuan et al., 2015b).

The short-term flood forecast, based on the numerical weather prediction (NWP) and hydrological models, is also an active area with significant attentions in China (Lu et al., 2008; Bao et al., 2012). The BoH has implemented a universal flood forecasting system software platform, China National Flood Forecasting System (CNFFS), towards an effective flood control (Liu and Zhang, 2005; Zhang and Liu, 2006). As for seasonal hydrological forecast, the ESP scheme has been in wide use in China (Li et al., 2008; He et al., 2013; Yang et al., 2014), while little attention has been paid in terms of CGCM-based forecast, except for a recent work focusing on the global major river basins (Yuan et al., 2015b). To this end, a hydrological model-based experimental hydrological monitoring and seasonal forecast 
framework for China was proposed (Figure 1). The framework seamlessly integrates the gauge-based historical simulation (Zhang et al., 2014), satellite-aided real-time monitoring (Zhang and Tang, 2015), CFSv2-based seasonal forecast into an operational system. In addition, an experimental seasonal hydrological forecasting system is being developed over Yellow River Basin based on a well-calibrated hydrologic model and multiple CGCMs.

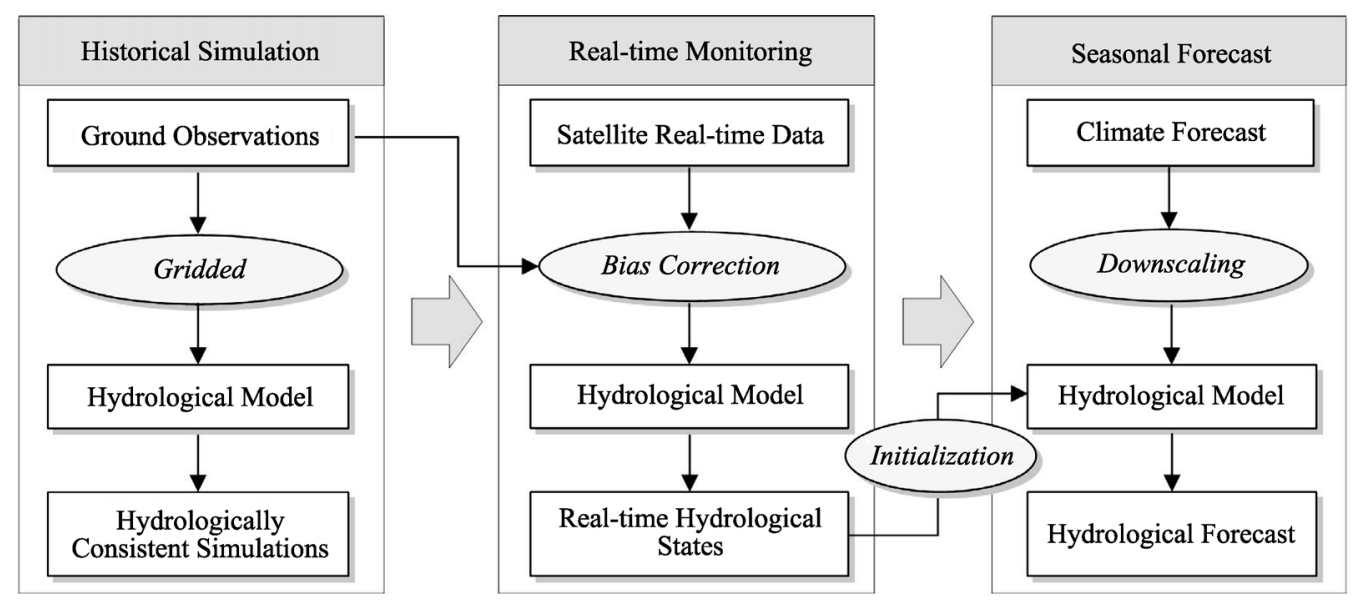

Figure 1 The configuration of hydrological monitoring and seasonal forecast framework for China

\section{Summary and future perspectives}

Over the past few decades, the hydrological monitoring technique has been largely improved along with the advances in remote sensing and numerical models. On one hand, many hydrological variables become acquirable in a real-time manner via automatic ground-based stations or satellite remote sensing. On the other hand, the calibrated hydrological model, being assisted by station and satellite data, has been demonstrated to provide reliable hydrological fluxes and states in real-time manner. A few satellite-assisted hydrological monitoring systems have been implemented across different scales and used for flood/drought diagnosis. Notably, there are considerable uncertainties residing in data generation and processing, which promotes the development of various mathematical methods to reduce or quantify such errors. While great progress has been achieved for hydrological monitoring, continued efforts are still in urgent need to improve the accuracy of measurement, such as by expanding the in-situ networks, and by improving the in-situ measurement techniques and satellite retrieve algorithms. In addition, it is of intense desire to incorporate the human-induced impacts (e.g., land cover, irrigation, and groundwater pumping) into land surface hydrological models by improving model parameterization scheme, with intent to simulate more realistic hydrological conditions.

The physical model-based hydrological forecast is becoming popular and implemented in two typical ways: (1) ESP-based framework that employs the ensemble of historical observations as the inputs of hydrological model and (2) climate model-based framework that drives the hydrological model with the downscaled outputs of climate forecast model. To date, considerable efforts have been devoted to assessing the reliability of seasonal hydrological prediction, such as by quantifying the contribution of initial conditions (ICs) and 
climate forecasts (CFs) to seasonal hydrological predictability. Concurrently, a few operational hydrological seasonal forecast systems, with the aid of real-time monitoring of ICs, the climate model outputs, and the appropriate statistical or dynamical downscaling methods, were explored using either single (climate and hydrological) model or multiple models. To better constrain the ICs, data assimilation technique is essential to improve the mode-derived prediction through blending the in-situ/satellite observations into hydrological monitoring.

In China, the BoH has made a large amount of hydrological monitoring and forecasting practices, for example, establishing the river regime monitoring network and short-term flood warning system across China. In contrast, the area of seasonal hydrological forecasts, especially that based on the climate model outputs, is still in infancy. In following, it should put more focus on the CGCM-based seasonal hydrological forecasts over China, in terms of quantifying the source of hydrological predictability within a consistent diagnosis framework, developing an operational seasonal forecast system in support of China Seasonal Drought Outlook, and assimilating the in-situ measurement of ICs into the operation system to reduce the uncertainties associated with the ICs.

Although many practices have been made for seasonal hydrological forecasts, many challenges still exist and need to be further addressed in near future. Firstly, it is essential to combine the statistical-based and the physical-based models, with intent to create a multimodel ensemble that is characterized with the largest model diversity. Secondly, further efforts are needed to develop a hydrological forecast system that seamlessly integrates the weather forecast and climate forecast (Yuan et al., 2014). This will greatly benefit integrating the achievement in short-term flood forecast and seasonal drought prediction. Furthermore, substantial attentions should be paid on investigating how to effectively incorporate human interventions into the operational monitoring and forecast system in the purpose of yielding more realistic hydrological conditions. Lastly, the final purpose for hydrological monitoring and seasonal forecasting is to provide useful guidance for the end users. Thus, to explore the solutions, which can effectively convert the probabilistic forecast consequences into the understandable and valuable information for the decision-makers (Demargne et al., 2014), is perhaps of equal to or greater importance than the development of such operational systems.

\section{References}

Ajami N K, Duan Q, Sorooshian S, 2007. An integrated hydrologic Bayesian multimodel combination framework: Confronting input, parameter, and model structural uncertainty in hydrologic prediction. Water Resources Research, 43: W01403.

Andreadis K M, Clark E A, Wood A W et al., 2005. Twentieth-century drought in the conterminous United States. Journal of Hydrometeorology, 6(6): 985-1001.

Andreadis K M, Lettenmaier D P, 2006. Assimilating remotely sensed snow observations into a macroscale hydrology model. Advances in Water Resources, 29: 872-886.

Bao H, Zhao L, 2012. Flood forecast of Huaihe River based on TIGGE Ensemble Prediction. Journal of Hydraulic Engineering, 43(2): 216-224.

Barnston A G, Tippett M K, L'Heureux M L et al., 2012. Skill of real-time seasonal ENSO model predictions during 2002-11: Is our capability increasing? Bulletin of the American Meteorological Society, 93: 631-651.

Bastola S, Misra V, Li H, 2013. Seasonal hydrological forecasts for watersheds over the southeastern United 
States for the boreal summer and fall seasons. Earth Interactions, 17: 1-22.

Below R, Grover-Kopec E, Dilley M, 2007. Documenting drought-related disasters: A global reassessment. The Journal of Environment \& Development, 16: 328-344.

Beven K J, Binley A M, 1992. The future of distributed models: model calibration and uncertainty prediction. Hydrological Processes, 6: 279-298.

Bierkens M, van Beek L, 2009: Seasonal predictability of European discharge: NAO and hydrological response time. Journal of Hydrometeorology, 10: 953-968.

Clark M P, Rupp D E, Woods R A et al., 2008. Hydrological data assimilation with the ensemble Kalman filter: Use of streamflow observations to update states in a distributed hydrological model. Advances in Water Resources, 31: 1309-1324.

Day G N, 1985. Extended streamflow forecasting using NWSRFS. Journal of Water Resources Planning and Management (ASCE), 111: 157-170.

De Lannoy G, Reichle R H, Arsenault K R et al., 2012. Multiscale assimilation of Advanced Microwave Scanning Radiometer-EOS snow water equivalent and Moderate Resolution Imaging Spectroradiometer snow cover fraction observations in northern Colorado. Water Resources Research, 48: W01522.

De Lannoy G, Reichle R H, Houser P R et al., 2010. Satellite-scale snow water equivalent assimilation into a high-resolution land surface model. Journal of Hydrometeorology, 11: 352-369.

De Sales F, Xue Y, 2013. Dynamic downscaling of CFS winter seasonal simulations with the UCLAETA regional climate model over the United States. Climate Dynamics, 41: 255-275.

Demargne J, 2014. The science of NOAA's operational hydrologic ensemble forecast service. Bulletin of the American Meteorological Society, 95: 79-98.

Di C L, Yang X H, Wang X C, 2014. A four-stage hybrid model for hydrological time series forecasting. PLoS One, 9(8): e104663.

Döll P, Fiedler K, Zhang J, 2009. Global-scale analysis of river flow alterations due to water withdrawals and reservoirs. Hydrology and Earth System Sciences, 13: 2413-2432.

Duan Q, Schaake J, Andréassian V et al., 2006. Model Parameter Estimation Experiment (MOPEX): An overview of science strategy and major results from the second and third workshops. Journal of Hydrology, 320: 3-17.

Duan Q, Sorooshian S, Gupta V, 1992. Effective and efficient global optimization for conceptual rainfall-runoff models. Water Resources Research, 28(4): 1015-1031.

Entekhabi D, Njoku E G, O’Neill P E et al., 2010. The Soil Moisture Active Passive (SMAP) Mission. Proceedings of the IEEE, 98: 704-716.

Evensen G, 1997. Advanced data assimilation in strongly nonlinear dynamics. Monthly Weather Review, 125: 1342-1354.

Ferguson I M, Maxwell R M, 2012. Human impacts on terrestrial hydrology: Climate change versus pumping and irrigation. Environmental Research Letters, 7: 044022.

Fujii H, Koike T, Imaoka K, 2009. Improvement of the AMSR-E algorithm for soil moisture estimation by introducing a fractional vegetation coverage dataset derived from MODIS data. Journal of the Remote Sensing Society of Japan, 29(1): 282-292.

Gao H, Tang Q, Ferguson C R et al., 2010. Estimating the water budget of major U.S. river basins via remote sensing. International Journal of Remote Sensing, 31: 3955-3978.

Garen D C, 1992. Improved techniques in regression-based streamflow volume forecasting. Journal of Water Resources Planning and Management (ASCE), 118: 654-670.

Gerten D, Rost S, von Bloh W et al., 2008. Causes of change in 20th century global river discharge. Geophysical Research Letters, 35: L20405.

Glahn H R, Lowry D A, 1972. The use of Model Output Statistics (MOS) in objective weather forecasting. Journal of Applied Meteorology and Climatology, 11(8): 1203-1211.

Haddeland I, Clark D B, Franssen W et al., 2011. Multimodel estimate of the global terrestrial water balance: Setup and first results. Journal of Hydrometeorology, 12: 869-884.

Hamlet A F, Lettenmaier D P, 1999. Columbia River streamflow forecasting based on ENSO and PDO climate 
signals. Journal of Water Resources Planning and Management (ASCE), 125(6): 333-341.

Han E, Crow W T, Holmes T et al., 2014. Benchmarking a Soil Moisture Data Assimilation System for Agricultural Drought Monitoring. Journal of Hydrometeorology, 15: 1117-1134.

He X, Zhao T, Yang D, 2013. Prediction of monthly inflow to the Danjiangkou reservoir by distributed hydrological model and hydro-climatic teleconnections. Journal of Hydroelectric Engineering, 32(3): 4-9.

Hirabayashi Y, Kanae S, Emori S et al., 2008. Global projections of changing risks of floods and droughts in a changing climate. Hydrological Sciences Journal, 53(4): 754-772.

Hirabayashi Y, Mahendran R, Koirala S et al., 2013. Global flood risk under climate change. Nature Climate Change, 3: 816-821.

Hong Y, Adler R F, Hossain F et al., 2007. A first approach to global runoff simulation using satellite rainfall estimation. Water Resources Research, 43: W08502.

Hou A Y, Kakar R K, Neeck S et al., 2014. The Global Precipitation Measurement Mission. Bulletin of the American Meteorological Society, 95: 701-722.

Houborg R, Rodell M, Li B et al., 2012. Drought indicators based on model-assimilated Gravity Recovery and Climate Experiment (GRACE) terrestrial water storage observations. Water Resources Research, 48: W07525.

Hu S S, Zheng H X, Liu C M et al., 2012. Assessing the impacts of climate variability and human activities on streamflow in the water source area of Baiyangdian Lake. Acta Geographica Sinica, 67(1): 62-70. (in Chinese)

Huang X, Xiao Q N, Barker D M et al., 2009. Four-dimensional variational data assimilation for WRF: Formulation and preliminary results. Monthly Weather Review, 137: 299-314.

Huffman G J, Bolvin D T, Nelkin E J et al., 2007. The TRMM multisatellite precipitation analysis (TMPA): Quasi-global, multiyear, combined-sensor precipitation estimates at fine scales. Journal of Hydrometeorology, 8(1): 38-55.

Kavetski D, Franks S W, Kuczera G, 2002. Confronting input uncertainty in environmental modeling. In: Duan Q, Gupta H, Sorooshian S et al. (eds.). Calibration of Watershed Models. Water Science and Application Series 6, American Geophysical Union, Washington D. C.: 49-68.

Kim S, Liu Y Y, Johnson F M et al., 2015. A global comparison of alternate AMSR2 soil moisture products: Why do they differ? Remote Sensing of Environment, 161: 43-52.

Koster R D, Mahanama S, Livneh B et al., 2010. Skill in streamflow forecasts derived from large-scale estimates of soil moisture and snow. Nature Geoscience, 3: 613-616.

Krishnamurti T N, Kishtawal C M, LaRow T E et al., 1999. Improved weather and seasonal climate forecasts from multimodel superensemble. Science, 285: 1548-1550

Krzysztofowicz R, Sigrest A A, 1999. Calibration of probabilistic quantitative precipitation forecasts. Weather Forecast, 14(3): 427-442.

Kwon H-H, Brown C, Xu K et al., 2009. Seasonal and annual maximum streamflow forecasting using climate information: Application to the Three Gorges Dam in the Yangtze River basin, China. Hydrological Sciences Journal, 54: 582-595.

Lan Y H, Ding Y J, Kang E et al., 2003. The relationship between ENSO cycle and high and low-flow in the upper Yellow River. Journal of Geographical Sciences, 13(1): 105-111.

Leng G, Huang M, Tang Q et al., 2013. Modeling the effects of irrigation on land surface fluxes and states over the conterminous United States: Sensitivity to input data and model parameters. Journal of Geophysical Research: Atmospheres, 118(17): 9789-9803.

Leng G, Huang M, Tang Q et al., 2014. Modeling the effects of groundwater-fed irrigation on terrestrial hydrology over the conterminous United States. Journal of Hydrometeorology, 15: 957-972.

Leng G Y, Tang Q H, Huang S Z et al., 2016. Assessments of joint hydrological extreme risks in a warming climate in China. International Journal of Climatology, 36: 1632-1642

Leng G Y, Tang Q H, Rayburg S, 2015. Climate change impacts on meteorological, agricultural and hydrological droughts in China. Global and Planetary Change, 126: 23-34.

Li H, Luo L, Wood E F, 2008. Seasonal hydrologic predictions of low-flow conditions over eastern USA during 
the 2007 drought. Atmospheric Science Letters, 9: 61-66.

Li H, Luo L, Wood E F, Schaake J, 2009. The role of initial conditions and forcing uncertainties in seasonal hydrologic forecasting. Journal of Geophysical Research: Atmospheres, 114: D04114.

Li Q Z, Yan N N, Zhang F F et al., 2010. Drought monitoring and its impacts assessment in Southwest China using remote sensing in the spring of 2010. Acta Geographica Sinica, 65(7): 771-780. (in Chinese)

Li X, Liu S M, Xiao Q et al., 2013. Heihe Watershed Allied Telemetry Experimental Research (HiWATER): Scientific objectives and experimental design. Bulletin of the American Meteorological Society, 94: 1145-1160

Li X, Toshio K, Mahadevan P, 2004. A very fast simulated re-annealing (VFSA) approach for land data assimilation. Computers \& Geosciences, 30: 239-248.

Li Y, Hu J, Wang J et al., 2008. Application of Ensemble Streamflow Prediction (ESP) to medium- and long-term water resources prediction. Journal of China Hydrology, 28(1): 25-27.

Liu F, Chen S L, Dong P et al., 2012, Spatial and temporal variability of water discharge in the Yellow River Basin over the past 60 years. Journal of Geographical Sciences, 22(6): 1013-1033.

Liu J, Zhang J, 2005. Development and prospects of hydrological forecasting technique in China. Journal of China Hydrology, 25(6): 1-5. (in Chinese)

Liu Y, Weerts A H, Clark M et al., 2012. Advancing data assimilation in operational hydrologic forecasting: Progresses, challenges, and emerging opportunities. Hydrology and Earth System Sciences, 16: 3863-3887.

Lu G H, Wu Z Y, Wen L et al., 2008. Real-time flood forecast and flood alert map over the Huaihe River Basin in China using a coupled hydro-meteorological modeling system. Science in China, Series E: Technological Sciences, 51(7): 1049-1063.

Luo L, Wood E F, 2007. Monitoring and predicting the 2007 U.S. drought. Geophysical Research Letters, 34 : L22702.

Luo L, Wood E F, 2008. Use of Bayesian merging techniques in a multimodel seasonal hydrologic ensemble prediction system for the eastern United States. Journal of Hydrometeorology, 9: 866-884.

Luo L, Wood E F, Pan M, 2007. Bayesian merging of multiple climate model forecasts for seasonal hydrological predictions. Journal of Geophysical Research: Atmospheres, 112: D10102.

Ma F, Yuan X, Ye A, 2015. Seasonal drought predictability and forecast skill over China. Journal of Geophysical Research, 120: 8264-8275.

Maurer E P, Lettenmaier D P, Mantua N J, 2004. Variability and potential sources of predictability of North American runoff. Water Resources Research, 40(9): W09306.

Maurer E P, Wood A W, Adam J C et al., 2002. A long-term hydrologically based dataset of land surface fluxes and states for the conterminous United States. Journal of Climate, 15: 3237-3251.

Milly P C D, Wetherald R T, Dunne K A et al., 2002. Increasing risk of great floods in a changing climate. Nature, 415: 514-517.

Mitchell K E, Lohmann D, Houser P R et al., 2004. The multi-institution North American Land Data Assimilation System (NLDAS): Utilizing multiple GCIP products and partners in a continental distributed hydrological modeling system. Journal of Geophysical Research: Atmospheres, 109: D07S90.

Mo K C, Lettenmaier D P, 2014. Hydrologic prediction over the conterminous United States using the National Multi-Model Ensemble. Journal of Hydrometeorology, 15: 1457-1472.

Mo K C, Shukla S, Lettenmaier D P et al., 2012. Do Climate Forecast System (CFSv2) forecasts improve seasonal SM prediction? Geophysical Research Letters, 39: L23703.

Nijssen B, Shukla S, Lin C Y et al., 2014. A prototype global drought information system based on multiple land surface models. Journal of Hydrometeorology, 15: 1661-1676.

Pagano T C, Garen D C, Perkins T R et al., 2009. Daily updating of operational statistical seasonal water supply forecasts for the western U.S. Journal of the American Water Resources Association (JAWRA), 45: 767-778.

Pan M, Sahoo A K, Troy T J, 2012. Multisource estimation of long-term terrestrial water budget for major global river basins. Journal of Climate, 25: 3191-3206.

Pan M, Wood E F, Wojcik R et al., 2008. Estimation of regional terrestrial water cycle using multi-sensor remote 
sensing observations and data assimilation. Remote Sensing of Environment, 112(4): 1282-1294.

Pozzi W, Sheffield J, Stefanski R et al., 2013. Toward global drought early warning capability: Expanding international cooperation for the development of a framework for monitoring and forecasting. Bulletin of the American Meteorological Society, 94: 776-785.

Raftery A E, Gneiting T, Balabdaoui F et al., 2005. Using Bayesian model averaging to calibrate forecast ensembles. Monthly Weather Review, 133: 1155-1174.

Robertson D E, Wang Q J, 2012. A Bayesian approach to predictor selection for seasonal streamflow forecasting. Journal of Hydrometeorology, 13: 155-171.

Rodell M, Houser P R, Jambor U et al., 2004. The Global Land Data Assimilation System. Bulletin of the American Meteorological Society, 85: 381-394.

Saha S, Moorthi S, Wu X R et al., 2014. The NCEP climate forecast system version 2. Journal of Climate, 27: 2185-2208.

Schaake J, Demargne J, Hartman R et al., 2007. Precipitation and temperature ensemble forecasts from single-value forecasts. Hydrology and Earth System Sciences, 4: 655-717.

Sheffield J, Ferguson C R, Troy T J et al., 2009. Closing the terrestrial water budget from satellite remote sensing. Geophysical Research Letters, 36: L07403.

Sheffield J, Wood E F, 2007. Characteristics of global and regional drought, 1950-2000: Analysis of soil moisture data from off-line simulation of the terrestrial hydrologic cycle. Journal of Geophysical Research: Atmospheres, 112: D17115.

Sheffield J, Wood E F, 2008. Global trends and variability in soil moisture and drought characteristics, 1950-2000, from observation-driven simulations of the terrestrial hydrologic cycle. Journal of Climate, 21: 432-458.

Sheffield J, Wood E F, Chaney N et al., 2014. A drought monitoring and forecasting system for sub-Sahara African water resources and food security. Bulletin of the American Meteorological Society, 95: 861-882.

Shukla S, Lettenmaier D P, 2011a. Seasonal hydrologic prediction in the United States: Understanding the role of initial hydrologic conditions and seasonal climate forecast skill. Hydrology and Earth System Sciences, 15: 3529-3538.

Shukla S, Lettenmaier D P, 2013. Multi-RCM ensemble downscaling of NCEP CFS winter season forecasts: Implications for seasonal hydrologic forecast skill. Journal of Geophysical Research: Atmospheres, 118: 10770-10790.

Shukla S, Steinemann A C, Lettenmaier D P, 2011b. Drought monitoring for Washington State: Indicators and applications. Journal of Hydrometeorology, 12: 66-83.

Shukla S, Sheffield J, Wood E F et al., 2013. On the sources of global land surface hydrologic predictability. Hydrology and Earth System Sciences, 17: 2781-2796.

Singh V P, Cui H, 2015. Entropy theory for streamflow forecasting. Environmental Processes, 2: 449-460.

Sinha T, Sankarasubramanian A, 2013. Role of climate forecasts and initial conditions in developing streamflow and soil moisture forecasts in a rainfall-runoff regime. Hydrology and Earth System Sciences, 17: 721-733.

Smith D M, Scaife A A, Kirtman B P, 2012. What is the current state of scientific knowledge with regard to seasonal to decadal forecasting. Environmental Research Letters, 7: 015602.

Staudinger M, Seibert J, 2014. Predictability of low flow: An assessment with simulation experiments. Journal of Hydrology, 519: 1383-1393.

Tang Q, Oki T, Kanae S et al., 2007. The influence of precipitation variability and partial irrigation within grid cells on a hydrological simulation. Journal of Hydrometeorology, 8: 499-512.

Tang Q, Oki T, Kanae S et al., 2008. Hydrological cycles change in the Yellow River basin during the last half of the 20th century. Journal of Climate, 21: 1790-1806.

Tang Q, Wood A W, Lettenmaier D P, 2009a. Real-time precipitation estimation based on index station percentiles. Journal of Hydrometeorology, 10: 266-277.

Tang Q, Gao H, Lu H et al., 2009b. Remote sensing: Hydrology. Progress in Physical Geography, 33: 490-509.

Tang Q, Peterson S, Cuenca R H et al., 2009c. Satellite-based near-real-time estimation of irrigated crop water consumption. Journal of Geophysical Research: Atmospheres, 114: D05114. 
Tapley B D, Bettadpur S, Ries J C et al., 2004. GRACE measurements of mass variability in the Earth system. Science, 305(5683): 503-505.

Thober S, Kumar R, Sheffield J et al., 2015. Seasonal soil moisture drought prediction over Europe using the North American Multi-Model Ensemble (NMME). Journal of Hydrometeorology, 16: 2329-2344.

Tobin K J, Bennett M E, 2010. Adjusting satellite precipitation data to facilitate hydrologic modeling. Journal of Hydrometeorology, 11: 966-978.

van Dijk A, Peña-Arancibia J L, Wood E F et al., 2013. Global analysis of seasonal streamflow predictability using an ensemble prediction system and observations from 6192 small catchments worldwide. Water Resources Research, 49: 2729-2746.

VanShaar J R, Haddeland I, Lettenmaier D P, 2002. Effects of land cover changes on the hydrologic response of interior Columbia River Basin forested catchments. Hydrological Processes, 16(13): 2499-2520.

Vogt J V, Barbosa P, Hofer B et al., 2011. Developing a European drought observatory for monitoring assessing and forecasting droughts across the European continent. AGU Fall Meeting Abstracts 1, NH24A-07.

Wang A, Lettenmaier D P, Sheffield J, 2011a. Soil moisture drought in China, 1950-2006. Journal of Climate, 24: 3257-3271.

Wang C, Duan Q, Gong W et al., 2014. An evaluation of adaptive surrogate modeling based optimization with two benchmark problems. Environmental Modelling \& Software, 60: 167-179.

Wang C, Duan Q, Tong C H et al., 2016. A GUI platform for uncertainty quantification of complex dynamical models. Environmental Modelling \& Software, 76: 1-12.

Wang E, Zhang Y, Luo J et al., 2011b. Monthly and seasonal streamflow forecasts using rainfall-runoff modeling and historical weather data. Water Resources Research, 47: W05516.

Wang X, Barker D M, Snyder C et al., 2008. A hybrid ETKF-3DVAR data assimilation scheme for the WRF model. Part I: Observing system simulation experiment. Monthly Weather Review, 136: 5116-5131.

Werner K, Brandon D, Clark M et al., 2004. Climate index weighting schemes for NWS ESP-based seasonal volume forecasts. Journal of Hydrometeorology, 5: 1076-1090.

Werner K, Brandon D, Clark M et al., 2005. Incorporating medium-range numerical weather model output into the ensemble streamflow prediction system of the National Weather Service. Journal of Hydrometeorology, 6 : $101-114$.

Westra S, Sharma A, Brown C et al., 2008. Multivariate streamflow forecasting using independent component analysis. Water Resources Research, 44: W02437.

Wilhite D A, 2000. Drought as a natural hazard: Concepts and definitions. In: Wilhite D A. Droughts: A Global Assessment. London: Routledge, 3-18.

Wood A W, Kumar A, Lettenmaier D P, 2005. A retrospective assessment of National Centers for Environmental Prediction climate model-based ensemble hydrologic forecasting in the western United States. Journal of Geophysical Research: Atmospheres, 110: D04105.

Wood A W, Lettenmaier D P, 2006. A test bed for new seasonal hydrologic forecasting approaches in the western United States. Bulletin of the American Meteorological Society, 87: 1699-1712.

Wood A W, Lettenmaier D P, 2008. An ensemble approach for attribution of hydrologic prediction uncertainty. Geophysical Research Letters, 35: L14401.

Wood A W, Maurer E P, Kumar A et al., 2002. Long-range experimental hydrologic forecasting for the eastern United States. Journal of Geophysical Research: Atmospheres, 107: 4429.

Wu H, Adler R F, Tian Y et al., 2014. Real-time global flood estimation using satellite-based precipitation and a coupled land surface and routing model. Water Resources Research, 50: 2693-2717.

Xia Y, Mitchell K, Ek M et al., 2012. Continental-scale water and energy flux analysis and validation for the North-American Land Data Assimilation System Project Phase 2 (NLDAS-2) (Part I): Intercomparison and application of model products. Journal of Geophysical Research: Atmospheres, 117: D03109.

Yang D W, Li C, Ni G H et al., 2004. Application of a distributed hydrological model to Yellow River basin. Acta Geographica Sinica, 59(1): 143-154. (in Chinese)

Yang L, Tian F, Sun Y et al., 2014. Attribution of hydrologic forecast uncertainty within scalable forecast win- 
dows. Hydrology and Earth System Sciences, 18: 775-786.

Yilmaz K K, Adler R F, Tian Y et al., 2010. Evaluation of a satellite-based global flood monitoring system. International Journal of Remote Sensing, 31(14): 3763-3782.

Yossef N C, Winsemius H, Weerts A et al., 2013. Skill of a global seasonal streamflow forecasting system, relative roles of initial conditions and meteorological forcing. Water Resources Research, 49: 4687-4699.

Yuan X, Liang X Z, 2011. Improving cold season precipitation prediction by the nested CWRF-CFS system Geophysical Research Letters, 38: L02706.

Yuan X, Ma Z, Pan M et al., 2015a. Microwave remote sensing of short-term droughts during crop growing seasons. Geophysical Research Letters, 42: 4394-4401.

Yuan X, Roundy J, Wood E F et al., 2015b. Seasonal forecasting of global hydrologic extremes: System development and evaluation over GEWEX basins. Bulletin of the American Meteorological Society, 96: 1895-1912.

Yuan X, Wood E F, Chaney N W et al., 2013a. Probabilistic seasonal forecasting of African drought by dynamical models. Journal of Hydrometeorology, 14: 1706-1720.

Yuan X, Wood E F, Roundy J K et al., 2013b. CFSv2-based seasonal hydroclimatic forecasts over the conterminous United States. Journal of Climate, 26: 4828-4847.

Yuan X, Wood E F, Liang M, 2014. Integrating weather and climate prediction: Toward seamless hydrologic forecasting. Geophysical Research Letters, 41: 5891-5896.

Yuan X, Wood E F, Ma Z, 2015c. A review on climate-model-based seasonal hydrologic forecasting: Physical understanding and system development. WIREs Water, 2: 523-536.

Zaitchik B F, Rodell M, Reichle R H, 2008. Assimilation of GRACE terrestrial water storage data into a land surface model: Results for the Mississippi River Basin. Journal of Hydrometeorology, 9(3): 535-548.

Zeng H W, Li L J, Li J Y, 2012. The evaluation of TRMM Multisatellite Precipitation Analysis (TMPA) in drought monitoring in the Lancang River Basin. Journal of Geographical Sciences, 22(2): 273-282.

Zhai J, Su B, Krysanova V et al., 2010. Spatial variation and trends in PDSI and SPI indices and their relation to streamflow in 10 large regions of China. Journal of Climate, 23: 649-663.

Zhang J, Liu Z, 2006. Hydrological monitoring and flood management in China. Frontiers in Flood Research, 305: 93-101.

Zhang X J, Tang Q, 2015. Combining satellite precipitation and long-term ground observations for hydrological monitoring in China, Journal of Geophysical Research: Atmospheres, 120: 6426-6443.

Zhang X J, Tang Q H, Pan M et al., 2014. A long-term land surface hydrologic fluxes and states dataset for China. Journal of Hydrometeorology, 15: 2067-2084.

Zhao H G, Yang S T, Wang Z W et al., 2015. Evaluating the suitability of TRMM satellite rain-fall data for hydrological simulation using a distributed hydrological model in the Weihe River catchment in China. Journal of Geographical Sciences, 25(2): 177-195.

Zhou T, Nijssen B, Huffman G J et al., 2014. Evaluation of real-time satellite precipitation data for global drought monitoring. Journal of Hydrometeorology, 15: 1651-1660. 